Marquette University

e-Publications@Marquette

Social and Cultural Sciences Faculty Research and

Publications

Social and Cultural Sciences, Department of

$1-1-2001$

\title{
The Effects of Expectancy Disconfirmation on Outcome Satisfaction in Police-Citizen Encounters
}

\author{
Michael D. Reisig \\ Michigan State University \\ Meghan S. Stroshine \\ Marquette University, meghan.stroshine@marquette.edu
}

Accepted version. Policing: An International Journal of Police Strategies \& Management, Vol. 24, No. 1 (2001): 88-99. DOI. This article is (C) Emerald Group Publishing and permission has been granted for this version to appear in e-Publications@Marquette. Emerald does not grant permission for this article to be further copied/distributed or hosted elsewhere without the express permission from Emerald Group Publishing Limited. 


\title{
The effects of expectancy disconfirmation on outcome satisfaction in police-citizen encounters
}

\author{
Michael D. Reisig and Meghan Stroshine Chandek \\ School of Criminal Justice, Michigan State University, \\ East Lansing, Michigan, USA
}

\begin{abstract}
This study tests the expectancy disconfirmation model using survey data from citizens who recently had police encounters. We find support for the expectancy disconfirmation model's primary hypothesis that increased disparity between expectations of police performance and actual service inversely affects citizen satisfaction with the way the police handle encounters. This finding persists for both voluntary (e.g. breaking and entering victims) and involuntary (e.g. traffic citations) police encounters. Our results also suggest that the scope of the expectancy disconfirmation model is limited. For example, the disparity between expectations and actual service is not correlated with citizen satisfaction with the police in general. Overall, the results show that the expectancy disconfirmation model is useful in that it provides conceptual guidance in an area of research that has been relatively void of theory, and can also help identify needed changes in police practices.
\end{abstract}

Keywords: Police, Satisfaction, Expectancy theory

\section{Introduction}

Contemporary police reform efforts (e.g. community policing) encourage departments to borrow innovative "best practices" from the private sector. Although the adoption of various managerial techniques has become more commonplace, there has been little effort to apply consumer-oriented theory to the policing context. One concept we believe is especially applicable to police-citizen encounters is expectancy disconfirmation. The expectancy 
disconfirmation model posits that consumer satisfaction is a response to the congruency between an individual's expectations and the actual performance of a product (Oliver, 1981). Applied to policing, then, satisfaction may be viewed as a function of the interrelationship between what citizens expect from the police and their perceptions of police performance (i.e. services rendered).

Our investigation of the expectancy disconfirmation model is guided by two primary objectives. First, we want to assess a series of hypotheses derived from the expectancy disconfirmation model in terms of directional accuracy (i.e. sign and significance) and explanatory power. Second, we investigate the scope of the expectancy disconfirmation model using data from both voluntary (i.e. crime victims) and involuntary (i.e. traffic tickets) policecitizen encounters, as well as different measures of satisfaction (i.e. global and specific). To accomplish these objectives, we use recently collected encounter-level survey data from a medium sized Midwestern city.

\section{Expectancy disconfirmation and the policing context}

The expectancy disconfirmation model can be conceptualized as a four-stage process. First, the consumer formulates expectations regarding a product. Expectations vary across consumers (Tse and Wilson, 1988). For example, based on his/her knowledge of a product, a consumer may estimate what the performance will be (Boulding et al., 1993; Oliver, 1980). On the other hand, expectations may also be more normative in nature, and thought of as what the consumer believes performance ought to be (Tse and Wilson, 1988; Woodruff et al., 1983). Second, the individual makes certain attributions regarding the performance of that product, and third, compares his/her perception of the product's performance against her/his initial expectations. The final stage in the expectancy disconfirmation process is the consumer's determination of how well the product "measures up" to his/her initial expectations. Here, expectations provide a baseline from which to compare perceptions of product performance. Accordingly, the individual may judge product performance to be better than, worse than, or equal to what he/she expected. The extent to which perceptions of performance "match" expectations dictates the type of disconfirmation the consumer experiences, and has a direct effect on satisfaction (Oliver, 1980). For example, a 
consumer might experience positive disconfirmation, wherein his/her expectations are exceeded (increases likelihood of satisfaction). Negative disconfirmation is another possibility, and occurs when the consumer's expectations are not met by product or service performance (decreases likelihood of satisfaction). Finally, zero disconfirmation occurs when performance matches expectations (no effect on satisfaction).

Although disconfirmation is hypothesized to have the largest effect on consumer satisfaction, research shows that disconfirmation is not the only direct effect. Expectations have also been found to directly affect satisfaction. For example, individuals with lower expectations often report higher levels of satisfaction. Similarly, the second component of disconfirmation (i.e. performance) has also been linked to outcome satisfaction. More specifically, as performance increases, so too do levels of consumer satisfaction (Oliver, 1981). Expectations and performance, therefore, are believed to have both direct and indirect effects on consumer satisfaction.

The expectancy disconfirmation model not only explains satisfaction with product performance, but also service satisfaction (Cadotte et al., 1987; Churchill and Suprenant, 1982; Oliver, 1977, 1980, 1981; Oliver and DeSarbo, 1988; Oliver and Swan, 1989; Swan and Trawick, 1981; Tse and Wilson, 1988). To date, however, few studies have used the expectancy disconfirmation model to assess citizen satisfaction with police service. Citizens who come into contact with police possess expectations similar to those held by private sector consumers. There is research to suggest that citizens possess certain expectations regarding what will happen or what they believe ought to happen during police encounters. For example, Carter (1985) found that Hispanic crime victims had clear expectations of police performance (i.e. investigative activities). Other studies, however, merely assume that normative standards of fairness (Smith and Hawkins, 1973), equality of police protection (Hahn, 1971), and justice (Jacob, 1971) exist among citizens. In other words, the practice of assuming that citizens possess clear expectations about how they ought to be treated by police is fairly common, but few studies have taken into account the differential levels of expectations regarding police service across citizens.

The link between police performance and citizen satisfaction has been well-documented in the policing literature. For example, 
several crime victim studies have documented that greater levels of police activity (e.g. investigative effort) are significantly correlated with higher levels of citizen satisfaction (Brandl and Horvath, 1991; Coupe and Griffiths, 1999; Percy, 1980; Shapland, 1983). Like most research in this area, these studies also assume expectations across citizens to be constant. In other words, previous researchers have failed to take into account the possibility that expectations of police service vary among citizens.

With but a few exceptions, researchers have yet to directly account for one of the most salient determinants of citizen satisfaction with police encounters - expectancy disconfirmation. Nevertheless, a few existing studies have addressed the disconnect between citizen expectations and police performance with regards to response time (Brandl and Horvath, 1991; Coupe and Griffiths, 1999; Pate et al., 1976; Percy, 1980). As we see it, there are two weaknesses with this body of research. First, extant research has focused primarily on police response. With little doubt this is an important component of citizen satisfaction, but citizens have other expectations regarding police service. Additionally, the emphasis on response time limits the scope of research to situations where citizens initiate contact. After all, officers also initiate contact with the public. A second limitation concerns the reliance on single item measures to capture the disparity between citizen expectations and actual service. For example, Brandl and Horvath (1991, p. 297) asked citizens whether police response was "faster than, shorter than, or about the same as expected”, Chandek and Porter (1998), in contrast, used multiple task-specific survey items, which included response time, to create a composite measure to assess the relationship between expectancy disconfirmation and citizen satisfaction with police encounters. Chandek and Porter's (1998) approach helps to ease concerns with the association between measurement error and the use of single item measures to investigate complex events, such as police-citizen encounters.

\section{Does type of contact matter?}

A significant body of literature has demonstrated that the type of contact one has with the police exerts a significant influence on satisfaction (Brandl et al., 1994; Bordua and Tifft, 1971; Dean, 1980; Furstenberg and Wellford, 1973; Scaglion and Condon, 1980; Smith and Hawkins, 1973). Studies generally differentiate "type" of police 
contact in one of two ways. First, researchers have classified policecitizen encounters as either "positive" or "negative/adverse". Second, researchers make a distinction between "voluntary" and "involuntary" police contacts. Voluntary contacts are those in which citizens mobilize the police (e.g. requesting assistance or reporting a crime). Voluntary contacts are believed to be more positive in nature because the police play a supportive role in the encounter. Involuntary contacts, on the other hand, are police-initiated and are characterized by a measurable increase in police use of legitimate authority and, perhaps, are more adversarial in nature (e.g. issuing traffic citations or arrests). It is not too surprising that existing research shows that positive or voluntary contacts are generally associated with higher satisfaction levels, while lower levels of satisfaction are reported by those who have experienced negative or involuntary encounters with the police (Dean, 1980). Existing research does not address, however, whether the expectancy disconfirmation model explains citizen satisfaction with involuntary police-citizen encounters.

\section{Research objectives}

The primary objective of this research was to assess a series of hypotheses derived from the expectancy disconfirmation model. In particular, we were interested in whether disparity between citizen expectations of police performance and the service that they actually receive affects satisfaction with police. Additionally, we explored two corollary hypotheses relating to the direct effects of:

1. (1) expectations of police service; and

2. (2) perceptions of police service on satisfaction with police.

Finally, we were also interested in the scope of the expectancy disconfirmation model. Previous researchers have successfully applied the expectancy disconfirmation model to a sample of victims; however, at this point in time we are uncertain whether the model is also applicable to more adversarial police-citizen encounters. Additionally, existing research suggests that the expectancy disconfirmation model explains citizen satisfaction with specific police encounters; however, whether the model explains more satisfaction with the police in general remains open to empirical inquiry. 


\section{Methods}

Reported here are the results from data analyses performed using two random probability samples of citizens who recently had contact with police in a medium sized Midwestern city (population approximately 125,000). The first sample, which includes citizens whose encounters with the police can be classified as "voluntary", comprises breaking and entering complainants $(n=211)[1]$. The second sample (or "involuntary" group) consists of citizens who received a traffic citation $(n=379)$ [2] (Table I).

\section{Variables}

Outcome measures. Two types of satisfaction measures are featured in the analyses presented below: specific (i.e. satisfaction with a particular incident) and global (i.e. satisfaction with police in general) (see Brandl et al., 1994, pp. 120-3). Specific satisfaction was a single survey item that asked respondents how satisfied they were with the way the study police department handled their most recent traffic stop or breaking and entering complaint. Global satisfaction was also measured using a single survey item that read, "How satisfied are you in general with the [name of city] Police Department?” Each satisfaction measure featured a four-point ordinal scale with $1=$ very dissatisfied to $4=$ very satisfied.

\section{[Table I]}

Expectancy disconfirmation variables. As noted previously, expectations vary in level and by type. Citizen expectations of police service are treated here as amalgams of expectations regarding what will and should happen, so we do not distinguish expectations by type. Rather, we focus on the citizen's expectation level.

The expectation variable was constructed using five survey items. Respondents in both samples were presented with a series of task-oriented items, and then asked whether they expected the officer to perform such acts $(1=$ yes, $O=$ no). In the breaking and entering sample these items were as follows:

1. (1) arrive on the scene in a reasonable amount of time;

2. (2) attempt to locate witnesses;

3. (3) search for and collect evidence;

4. (4) give advice on how to prevent future break-ins; and 
5. (5) call you after the initial report was taken to inform you of the status of your case.

For the traffic encounter sample, the five task-oriented items included:

1. (1) inform you as to why you were stopped;

2. (2) inform you as to how to take care of the violation;

3. (3) complete the encounter in a reasonable amount of time;

4. (4) answer your questions concerning the stop; and

5. (5) wait for you to merge back into traffic after the encounter.

Expectation ranged from $\mathrm{o}=$ no expectations to $5=$ high expectations[3].

Service received was constructed using items similar to those included in the expectation variable. The primary difference between these two sets of items is that service received includes items that asked participants whether tasks (e.g. locate witnesses and answer questions concerning the stop) were actually carried out ( $1=$ yes and $o=$ no). Service received also ranged from o to 5 , where an increase in variable score reflected an increase in the number of tasks carried out by the police.

Finally, disconfirmation was constructed using information from the expectation and service received scales. More specifically, service was subtracted from expectation. Doing so generated scores ranging from -5 (negative disconfirmation) to +5 (positive disconfirmation). Next, this information was recoded whereby $1=$ positive disconfirmation, $6=$ zero confirmation, and $\mathbf{1 1}=$ negative disconfirmation[4]. We expected to observe an inverse relationship between disconfirmation and satisfaction with police.

Control variables. It is likely that variation in satisfaction with police exists between citizens with different backgrounds. In fact, previous research has shown that demographic characteristics, such as race and age, are associated with general and encounterspecific attitudes towards police (Bordua and Tifft, 1971; Brandl and Horvath, 1991; Brandl et al., 1994; Furstenburg and Wellford, 1973; Percy, 1980; Smith and Hawkins, 1973). To adjust for this occurrence, we included three demographic measures as statistical controls in the multivariate analysis: minority $(1=$ minority citizen, $\mathrm{o}=$ Caucasian citizen); male $(1=$ male, $\mathrm{o}=$ female $)$, and age (respondent's age measured in years). 
Research has revealed also that the officer's demeanor during an encounter also affects citizen satisfaction with police (Brandl and Horvath, 1991; Chandek, 1999; Chandek and Porter, 1998). With this in mind, we included one additional control variable, police behaviour. This variable was a five-item additive scale that indicated whether the officer was courteous, sarcastic (reverse scored), business-like, friendly, and took time to listen. Each of these items originally featured a response set with $1=$ yes and $\mathrm{o}=$ no. Police behaviour was coded so that higher scores indicated more positive ratings. Police behaviour had a mean interitem correlation of $0.51[5]$.

\section{Results}

One objective of this study was to assess a set of hypotheses derived from the expectancy disconfirmation model. For example, we were interested in the association between service received and citizen satisfaction. The correlation matrix located in Table II provides results that shed some light on this concern, as well as related inquiries. The findings indicate that the level of service an individual receives is related to her/his satisfaction with the way the police handled the incident among breaking and entering complainants $(r=0.49)$ and individuals who received a traffic citation $(r=0.57)$. In contrast, the correlation coefficients between expectation and incident-specific satisfaction in both samples appear weak. Overall, then, the zero-order correlations provide partial support for the corollary hypotheses that the unique components of disconfirmation (i.e. expectation and service received) are directly associated with how satisfied respondents are with the way the police handled their most recent traffic stop or breaking and entering complaint.

\section{[Table II]}

Table II also shows that disparity between citizen expectations and the service they received is inversely related to satisfaction with the encounter. Not only is the estimate in the hypothesized direction, but the magnitude of the association between disconfirmation and specific satisfaction is moderate-tostrong for both the breaking and entering sample $(r=-0.32)$ and the traffic encounter sample $(r=-0.53)$. It may be, however, that disconfirmation is confounded by individual demographic 
characteristics (e.g. age, race, and sex) or by police behaviour that is not task-oriented. To investigate further, we used ordinary least squares (OLS) regression to measure the effects of disconfirmation, net of statistical controls, on specific satisfaction in both samples (see Table III)[6].

\section{[Table III]}

Results from the OLS models, which are presented in standardized form, reveal that the most salient determinant of specific satisfaction is police behaviour. In other words, the perception of how one is treated in either a traffic encounter or as a breaking and entering complainant has the most influence on citizen satisfaction with the way police handle the encounter. The effects of disconfirmation, however, persist in the specific satisfaction OLS equations. In terms of directional accuracy, then, these findings support the hypothesis that the congruence between expectations and perceptions of police service affects levels of satisfaction with the way police handle an encounter[7].

Finally, Table III shows that disconfirmation performs poorly with regards to predicting global satisfaction in the traffic citation sample, as well as the breaking and entering sample. Police behaviour, on the other hand, is significantly correlated with global satisfaction. It is also interesting to note that, in comparative terms, our models explain less of the variance associated with global satisfaction than specific satisfaction in both the traffic sample (i.e. 25 per cent versus 46 per cent) and the breaking and entering sample (i.e. 23 per cent versus 37 per cent).

\section{Discussion}

The analyses presented above support the central premise of the expectancy disconfirmation model when applied to the policing context: citizen satisfaction with police encounters is a product of the congruence between individual expectations of service and the perceptions of the actual service rendered. The results for the direct effects of the unique components of disconfirmation, on the other hand, were mixed. The level of service an individual received was correlated with levels of satisfaction with the way police handled the encounter. We did not observe a similar effect, however, between an individual's expectation level and specific satisfaction. 
What are the policy implications of these findings? The good news is that the expectancy disconfirmation model provides police executives with a valuable framework that can be used to improve performance in terms of citizen satisfaction with police encounters (see Bayley, 1994, pp. 96-101; Reisig, 1999). Doing so entails that, at a minimum, police work to reduce disparity between citizen expectations and the tasks police perform during encounters. To accomplish this objective, police need to identify encounter-specific expectations that they have in common with the citizenry. Such a task may benefit from citizen input that may be obtained using a variety of techniques (e.g. focus groups, surveys, or community forums). Next, police managers need to integrate the information they generate into officer training programs and provide incentives to help ensure that officers carry out these tasks on a consistent basis.

Our investigation into the scope of the expectancy disconfirmation model produced mixed findings. First, we found support for the notion that the expectancy disconfirmation model is applicable to both voluntary and involuntary police-citizen encounters. The findings regarding involuntary encounters, however, raise an interesting question. Given that receiving a traffic citation represents a relatively subtle form of coercive authority, how well would the expectancy disconfirmation model perform if it were to be applied to police-citizen encounters further down the coercion continuum, such as arrests? We believe future research in this area would help further assess the scope of expectancy disconfirmation in the policing context, and help determine whether police can do anything to improve the service of such an unpleasant experience.

A second set of findings related to the scope of expectancy disconfirmation is that no relationship was observed between disconfirmation and global satisfaction with the police. The difference in the coefficient of determination between the specific and global satisfaction model for both samples leads one to tentatively conclude that the global models were not fully specified. This is not breaking news given that recent research suggests that experience with police may not be the most salient determinant of global satisfaction. Using a sample of residents who had and had not recently come into contact with police, Reisig and Parks (2000) found that psychologically-based, perceptual assessments of 
neighbourhood quality of life issues account for the greatest proportion of variation in global satisfaction with police at the individual-level. The effects of quality of life measures on satisfaction among only citizens who have recently had contact with police, however, remains unknown. In sum, then, police practitioners would be well advised to maintain their ambitions of improving citizen satisfaction using the expectancy disconfirmation model within the bounds of encounter-level satisfaction. Empirical evidence suggests that steps taken to better meet or even exceed citizen expectations at the encounter-level will have only indirect effects on how citizens feel about the police in general.

Despite our interest in the expectancy disconfirmation model, the results indicate that police behaviour is the most salient determinant of satisfaction (both specific and global) among citizens encountering the police (both voluntarily and involuntarily). If citizen satisfaction is used as a performance measure of police-citizen encounters, then these findings support efforts to encourage and train officers to display civility when interacting with citizens. In terms of encounter-level citizen satisfaction, the effect of outwardly polite officer demeanor is difficult to overstate.

Citizen satisfaction studies have become increasingly common in the police literature since the mid-1960s. Despite the enormity of extant research in this area, an overwhelming number of citizen satisfaction with police studies are theoretical in nature. As a result, researchers have been unable to provide a priori propositions, and instead offer up little more than post hoc interpretations of data. If a more sophisticated understanding of citizen satisfaction with police is to emerge, then the application of theoretical models is a necessity. We believe that the use of the expectancy disconfirmation model in encounter-level satisfactionbased police research will not only help to better understand the dynamics of citizen attitudes towards police, but can also help police practitioners to make incremental changes to existing training programs and police practices that will potentially improve citizen evaluations of their work.

\section{Notes}

1. A telephone survey was the primary means of data collection for the breaking and entering sample. The survey was administered using nonsworn police cadets. Contact with all citizens who had filed a breaking 
and entering complaint with the department over the nine months prior to the study was attempted. A total of 715 citizens were telephoned. However, 146 complainants could not be contacted because their telephone service was disconnected. This left a sample of 569 residents. Of these citizens, 250 individuals were chronically unavailable and repeated attempts to contact them were not successful. The participation rate was quite high among those who were contacted (approximately 94 per cent). Only 20 complainants refused to participate. Overall, 299 citizens took the time to answer the questions posed by the cadets, which resulted in a response rate of 52.5 per cent, respectively. Prior to the interview, citizens were informed that their participation was voluntary, and that their responses would be kept strictly confidential. When compared to official records, the sample appeared to slightly overrepresent males, minorities, and burglaries of unattached, nonresidential dwellings. For this analysis, breaking and entering cases involving businesses $(n=46)$ were not included because we were unable to determine whose expectations were most important, as well as determine which employee had contact with police. Finally, we found that the former and the latter were often times different people. The original sample size was further reduced by 42 cases because of missing information.

2. A mail survey was used as the data collection procedure for the traffic encounter sample. The study police department supplied the senior author with an exhaustive list of individuals who had been issued a traffic citation in March 1999 ( $n=2,360)$. Next, 1,237 citizens were then randomly selected to participate in the study. All those selected to participate were sent a questionnaire and a postage prepaid return envelope. A second mailing went out to nonrespondents two weeks later. Follow-up phone calls to encourage participation were made shortly after the second wave was distributed. In all, 389 usable surveys were returned which resulted in a response rate of 31.4 per cent. Police records indicate that our sample is representative in terms of sex, age, and type of violation (i.e. moving and non-moving). However, the original sample overrepresented citizens involved in traffic accidents. The original sample size was reduced by ten cases because of missing information.

3. One of the researchers (Reisig) worked closely with members representing various ranks from the participating police department to identify task-oriented behaviours that citizens and department supervisors expect from officers during both types of encounters. "Taskoriented behaviour" was defined by the group as something the officer does for the citizen, such as provide information. Task-oriented behaviours were conceptualized as distinct from items that reflect officer demeanor (e.g. courteousness), which were viewed as more general expectations of social behaviour that were not specific to police-citizen encounters. The list of expectations of task-oriented behaviours listed here is not exhaustive, and future work in this area may reveal items that were inadvertently overlooked. 
4. We sought to improve upon earlier work when developing the coding scheme employed in this analysis. For example, Chandek's (1999) "expectation fulfilment" variable only captures one side of the disconfirmation continuum (i.e. from zero to negative disconfirmation). Doing so ignores the positive effects hypothesized to result from exceeding expectations, and results in the coding of a variable that is skewed in the positive direction. Although Chandek and Porter (1998) used similar question formats to derive citizen expectations and determine actual police services rendered, the authors needlessly discarded information by collapsing the variable into a three-point ordinal scale ranging from $1=$ negative to $3=$ positive disconfirmation.

5. Although the breaking and entering survey also featured five survey items where $1=$ yes and $\mathrm{o}=$ no, the individual survey items used to construct police behaviour differed slightly. For breaking and entering complainants, police behaviour included whether the officer was courteous, understanding, appeared concerned, took time to listen, took the situation seriously. The mean inter-item correlation was 0.64 .

6. The multivariate models presented here were re-estimated using an ordered probit model. The results substantively mirrored (i.e. sign and significance) the findings of the OLS models presented in Table III.

7. We also investigated the effects of each disconfirmation item on specific satisfaction by estimating OLS models for each sample. For citizens who received a traffic citation, officers who did not answer the questions concerning the stop had the strongest effect $\beta=-0.30$ ) on satisfaction with the encounter. As might be expected, officers who did not arrive on the scene had the strongest effect $\beta=-0.30$ ) on satisfaction with the way officers handled burglary complaints.

\section{References}

Bayley, D. (1994), Policing for the Future, Oxford University Press, New York, NY.

Bordua, D. and Tifft, L. (1971), "Citizen interviews, organizational feedback, and policecommunity relations decisions", Law and Society Review, Vol. 6, pp. 155-82.

Boulding, W., Kalra, A., Staeline, R. and Zeithaml, V. (1993), “A dynamic process model of service quality: from expectations to behavioral intentions", Journal of Marketing Research, Vol. 30, pp. 7-27.

Brandl, S. and Horvath, F. (1991), "Crime victim evaluation of police investigative performance”, Journal of Criminal Justice, Vol. 19, pp. 293-305.

Brandl, S., Frank, J., Worden, R. and Bynum, T. (1994), "Global and specific attitudes toward the police: disentangling the relationship", Justice Quarterly, Vol. 11, pp. 119-34.

Cadotte, E., Woodruff, R. and Jenkins, R. (1987), "Expectations and norms in models of consumer satisfaction", Journal of Marketing Research, Vol. 24, pp. 305-14.

Carter, D. (1985), "Hispanic perception of police performance: an empirical assessment”, Journal of Criminal Justice, Vol. 12, pp. 487-500.

Chandek, M. (1999), "Race, expectations and evaluations of police performance: an empirical assessment", Policing: An International Journal of Police Strategies and Management, Vol. 22, pp. 675-95. 
Chandek, M. and Porter, C. (1998), "The efficacy of expectancy disconfirmation in explaining crime victim satisfaction with the police”, Police Quarterly, Vol. 1, pp. 21-40.

Churchill, G. and Surprenant, C. (1982), "An investigation into the determinants of customer satisfaction", Journal of Marketing Research, Vol. 19, pp. 491-504.

Coupe, T. and Griffiths, M. (1999), "The influence of police actions on victim satisfaction in burglary investigations", International Journal of the Sociology of Law, Vol. 27, pp. 413-31.

Dean, D. (1980), "Citizen ratings of the police: the difference police contact makes", Law and Policy Quarterly, Vol. 2, pp. 445-71.

Furstenburg, F. and Wellford, C. (1973), "Calling the police: the evaluation of police service”, Law \& Society Review, Vol. 8, pp. 393-406.

Hahn, H. (1971), "Ghetto assessments of police protection and authority", Law \& Society Review, Vol. 6, pp. 183-93.

Jacob, H. (1971), "Black and white perceptions of justice in the city", Law \& Society Review, Vol. 6, pp. 69-89.

Oliver, R. (1977), "Effect of expectation and disconfirmation on postexposure evaluations: an alternative interpretation", Journal of Applied Psychology, Vol. 62, pp. 480-6.

Oliver, R. (1980), "A cognitive model of the antecedents and consequences of satisfaction decisions", Journal of Marketing Research, Vol. 17, pp. 460-9.

Oliver, R. (1981), "Measurement and evaluation of satisfaction processes in retail settings", Journal of Retailing, Vol. 57, pp. 25-48.

Oliver, R. and DeSarbo, W. (1988), "Response determinants in satisfaction judgments", Journal of Consumer Research, Vol. 14, pp. 495-507.

Oliver, R. and Swan, J. (1989), "Equity and disconfirmation perceptions as influences on merchant and product satisfaction", Journal of Consumer Research, Vol. 16, pp. 372-83.

Pate, A., Ferrara, A., Bowers, R. and Lorence, J. (1976), Police Response Time: Its Determinants and Effects, The Police Foundation, Washington, DC.

Percy, S. (1980), "Response time and citizen evaluation of the police", Journal of Police Science and Administration, Vol. 8, pp. 75-86.

Reisig, M. (1999), Measuring Performance in the Era of Community Policing, Regional Community Policing Institute, East Lansing, MI.

Reisig, M. and Parks, R. (2000), "Experience, quality of life, and neighbourhood satisfaction: a hierarchical analysis of satisfaction with police", Justice Quarterly, Vol. 17, pp. 607-30.

Scaglion, R. and Condon, R. (1980), "Determinants of attitudes towards city police”, Criminology, Vol. 17, pp. 485-95.

Shapland, J. (1983), "Victim-witness services and the needs of the victim", Victimology, Vol. 8, pp. 233-7.

Smith, P. and Hawkins, R. (1973), "Victimization, types of citizen-police contacts, and attitudes towards the police", Law \& Society Review, Vol. 8, pp. 135-52.

Swan, J. and Trawick, F. (1981), "Disconfirmation of expectations and satisfaction with a retail service", Journal of Retailing, Vol. 57, pp. 49-67.

Tse, D. and Wilson, P. (1988), "Models of consumer satisfaction formation: an extension", Journal of Marketing Research, Vol. 25, pp. 204-12.

Woodruff, R., Cadotte, E. and Jenkins, R. (1983), "Modeling consumer satisfaction processes using experience-based norms", Journal of Marketing Research, Vol. 20, pp. 296-304. 
Table I. Descriptive statistics by sample

\begin{tabular}{|c|c|c|c|c|}
\hline \multirow[b]{2}{*}{ Variables } & \multicolumn{2}{|c|}{ Traffic } & \multicolumn{2}{|c|}{ Breaking and entering } \\
\hline & Mean & SD & Mean & SD \\
\hline Specific satisfaction & 2.70 & 1.15 & 3.24 & 1.00 \\
\hline Global satisfaction & 2.71 & 1.04 & 3.21 & 0.96 \\
\hline Expectation & 4.22 & 0.91 & 3.75 & 1.31 \\
\hline Service received & $3 \cdot 71$ & 1.41 & 2.99 & 1.35 \\
\hline Disconfirmation & 6.53 & 1.47 & 6.83 & 1.53 \\
\hline Police behavior & 3.67 & 1.70 & 4.45 & 1.29 \\
\hline Minority & 0.35 & 0.48 & 0.29 & 0.46 \\
\hline Male & 0.58 & 0.49 & 0.40 & 0.49 \\
\hline Age & 5.02 & 13.80 & 38.98 & $13 \cdot 52$ \\
\hline$n$ & \multicolumn{2}{|c|}{379} & \multicolumn{2}{|c|}{211} \\
\hline
\end{tabular}

Table II. Bivariate relationships by sample

$\begin{array}{llllllllllc} & & 1 & 2 & 3 & 4 & 5 & 6 & 7 & 8 & 9 \\ \text { Specific satisfaction } & 1 & & 0.51 & 0.06 & 0.57 & -0.53 & 0.65 & -0.18 & -0.11 & 0.11 \\ \text { Global satisfaction } & 2 & 0.68 & & 0.08 & 0.39 & -0.33 & 0.46 & -0.18 & 0.01 & 0.19 \\ \text { Expectation } & 3 & 0.11 & 0.10 & & 0.31 & 0.31 & 0.07 & -0.11 & -0.06 & -0.08 \\ \text { Service received } & 4 & 0.49 & 0.32 & 0.34 & & -0.80 & 0.64 & -0.15 & -0.05 & 0.10 \\ \text { Disconfirmation } & 5 & -0.32 & -0.16 & 0.55 & -0.59 & & -0.59 & 0.09 & 0.01 & -0.15 \\ \text { Police behaviour } & 6 & 0.61 & 0.47 & 0.11 & 0.44 & -0.30 & & -0.14 & -0.10 & 0.20 \\ \text { Minority } & 7 & 0.04 & -0.01 & 0.03 & 0.02 & 0.02 & 0.08 & & -0.01 & -0.02 \\ \text { Male } & 8 & 0.10 & 0.10 & 0.04 & 0.01 & 0.05 & 0.14 & -0.14 & & -0.09 \\ \text { Age } & 9 & 0.00 & 0.08 & -0.08 & 0.04 & -0.13 & 0.04 & -0.18 & 0.11 & \end{array}$

Note: Bivariate associations for the breaking and entering sample are located below the diagonal of the correlation matrix, and the associations for the traffic sample can be found above the diagonal

Table III. Standardized regression coefficients by sample

\begin{tabular}{lcccc} 
& \multicolumn{2}{c}{ Traffic } & \multicolumn{2}{c}{ Breaking and entering } \\
& Specific & Global & Specific & Global \\
Disconfirmation & $-0.231^{* * * * *}$ & -0.079 & $-0.173^{* *}$ & -0.040 \\
Police behaviour & $0.504^{* * *}$ & $0.381^{* * *}$ & $0.534^{* * *}$ & $0.456^{* * *}$ \\
Minority & -0.073 & $-0.117^{*}$ & 0.014 & -0.033 \\
Male & -0.057 & 0.049 & 0.047 & 0.030 \\
Age & -0.026 & $0.113^{*}$ & -0.031 & 0.038 \\
$R^{2}$ & 0.46 & 0.25 & 0.37 & 0.23 \\
F & $64.81^{* * *}$ & $24.30^{* * *}$ & $24.90^{* * *}$ & $12.01^{* * *}$
\end{tabular}

Notes: ${ }^{*} p<0.05 ;{ }^{* *} p<0.01,{ }^{* * *} p<0.001$ 